\title{
Relationship Between Unemployment Rate and Shadow Economy in Nigeria: A Tado-Yamamoto Approach
}

\author{
Felicia C. Abada ${ }^{1}$, Charles O. Manasseh ${ }^{2}$, Ifeoma C. Nwakoby ${ }^{2}$, Ngozi Franca Iroegbu ${ }^{3}$, Johnson I. Okoh ${ }^{4}$, Felix C. \\ Alio $^{2}$, Adedoyin I. Lawal ${ }^{5} \&$ Onyinye J. Asogwa ${ }^{6}$ \\ ${ }^{1}$ Social Sciences Unit, School of General Studies, University of Nigeria, Nsukka, Nigeria \\ ${ }^{2}$ Department of Banking \& Finance, University of Nigeria Enugu Campus, Nsukka, Enugu State, Nigeria \\ ${ }^{3}$ Department of Business Management, Alex Ekwueme Federal University Ndufu Like, Ikwo, Nigeria \\ ${ }^{4}$ Department of Financial Studies, National Open University of Nigeria, Abuja, Nigeria \\ ${ }^{5}$ Department of Accounting \& Finance, Landmark University, Omu Aran, Nigeria \\ ${ }^{6}$ Department of Economics, Federal University, Wukari, Nigeria
}

Correspondence: Ngozi Franca Iroegbu, Department of Business Management, Alex Ekwueme Federal University Ndufu Like, Ikwo, Nigeria.

Received: May 29, 2020

Accepted: July 10, 2020

Online Published: February 4, 2021

doi:10.5430/ijfr.v12n3p271

URL: https://doi.org/10.5430/ijfr.v12n3p271

\begin{abstract}
This study assessed the nature of the relationship between the size of the shadow economy and unemployment rate in Nigeria using the Tado-Yamamoto approach over the period 1980Q1 to 2018Q4. The size of the shadow economy in Nigeria was determined using the parsimonious model of MIMIC (4-1-2) having four multiple causes (tax burden, self-employment, social benefits paid by the government and unemployment rate) and two indicators (index of real Gross Domestic Product and currency ratio (M1/M2)). The estimated relationship of the size of shadow economy as percentage of official GDP recorded 13.78\% at the beginning of the first quarter of 1980 before fluctuating to $8.23 \%$ in the third quarter of 2009. The existence of a strong and positive association between the unemployment rate and shadow economy is affirmed by the estimated coefficient of determination (0.89) which confirmed the capacity of the shadow economy to absorb the unemployed workers from the official economy in Nigeria. Evidence exists from the Tado and Yamamoto (1995) causality test which revealed a causal relationship emanating from unemployment rate to the size of shadow economy. This was confirmed by the Modified Wald (MWald) test which demonstrated that a strong unidirectional causality running from unemployment rate to the size of shadow economy exists at $1 \%$ level of significance.
\end{abstract}

Keywords: shadow economy, unemployment, Tado-Yamamoto approach

\section{Introduction}

Nigeria as a nation has failed to achieve the required employment and income levels in the formal economy despite the abundant national resources at its discretion. These economic anomalies encourage the active labour force to explore other income generating opportunities outside the official economy. Despite the growing activities of the shadow economy, information on the magnitude, causes, qualities, dynamics, and operations of a shadow economy is still inadequate (Oduh et al. 2008). Simply put, any economic activity functioning outside the ambit of government assessment can be described as shadow, informal, unofficial, irregular, parallel, hidden, subterranean, invisible, unregulated, unrecorded, unofficial, backyard, invisible, black, gray, clandestine, illegal, under-ground and/or moonlight economy (Feige, 1990; Thomas, 1992; Abumere, 1995; Schneider \& Enste, 2000; and Ogbuabor \& Malaolu, 2013). People typically operate within the shadow economy as a result of increased tax burden and social security contributions, intricacies with the tax system, tight labour markets regulations, growing unemployment rate, government failure, forced reduction in official working hours, increased rate of inflation, interest rate, early retirement and fast decline in tax confidence. For instance, Enste (2003) suggests that the reduction in the working hours contrary to workers' choices multiplies the possible hours spent in the shadow economy. Also, the disparity between the total cost of labour in the official economy and after-tax labour earnings offers an incentive to sell more in the shadow economy, thereby discouraging individuals receiving welfare payments from seeking work in the 
official economy. Furthermore, an increased and tight government regulation reduces individuals' choices in the official economy. Thus, shifting cost to workers provides the motivation for employees to offer their services to the shadow economy (Schneider \& Enste, 2000).

The role the shadow economy plays in Nigeria with respect to employment creation, performance, use of local skills, self-reliance and increased ties among sectors cannot be overemphasized. Therefore, despite the decline in per-capita income and wage employment in Nigeria, the sector has made significant contribution to Gross Domestic Product (GDP) and employment as well as economic development (Omisan, 1999). To some extent, these activities are perpetrated by individuals and unregistered sole proprietorships and in some instances, joint partnerships in both rural and urban settlements. Economic activities in the shadow economy that are mostly ignored include the following: manufacturing, construction, trade and commerce. Other salient services are the repair of vehicles, radios, clocks and television sets; automobile mechanics, woodwork, tailoring, electricians, refrigerators, hair-dressing, weaving, furniture, blacksmithing, cobblers, upholstery, printing, bricks laying, carpentry, laundry services and other sundry works which vary from urban to rural areas (Ogbuabor \& Malaolu, 2013; Olowu \& Okotoni, 1996). It is therefore obvious that information on the scope of the shadow economy, who engages in what, how often is the activity done and to what extent, is crucial to effective decision making regarding the allocation of Nigeria's resources. Unfortunately, relevant data on the goods and labour market in the shadow economy is either scarce or non-existent because the participating individuals do not want to be identified. This also results in rampant tax evasion as the income generated from the shadow economy is usually unrecorded (Fasanya \& Onakoya, 2012).

According to Tanzi (1999), the relationship between the shadow economy and unemployment rate is vague owing to the fact that, those working in the official economy may also partake in the shadow economy albeit on a temporary basis. Likewise, those who are legitimately employed on a part-time basis can afford the spare time to engage in shadow economic activities. However, consistent with the works of Giles and Tedds (2002), Boeri and Garibaldi (2002) and Dell' Anno and Solomon (2007) two divergent and frail ideas have emerged to explain the connection between unemployment rate and the shadow economy. They argued that, unemployment rate is not only related to shadow economy negatively. They further argued that increase in unemployment rate with a corresponding increase in the shadow economy could contribute positively to the growth of output since the unemployed workers chose to spend their extra time working in the shadow economy. Furthermore, Ajakaiye and Akerele (1996), Oduh et al (2008), Ogbuabor and Malaolu (2013) suggested that Nigeria's shadow economy remains a challenge since it has not been thoroughly studied nor understood. Notwithstanding the considerable literature on the size and causes of the shadow economy in Nigeria, there exists a paucity of research on the relationship between the shadow economy and unemployment rate in Nigeria. Therefore, this study is aimed at assessing if the shadow economy serves as shield in absorbing unemployed workers, and also to determine the causal relationship between unemployment rate and the shadow economy in Nigeria for the period 1980Q1 to 2018Q4 using the Toda-Yamamoto approach. The paper is organized into seven sections. Following the introductory piece is section two which conceptualizes the study. Sections three and four cover the review of relevant theoretical literature as well as empirical studies on the shadow economy. The data and methodology employed in the study are shown in section five, while the empirical results are presented in section six. In section seven, the study is concluded.

\section{Review of Related Literature}

In this section, definitions and explicit explanations are provided on the concepts of shadow economy and unemployment as used in the study. The essence is to make the discussions insightful and consistent in analyzing the objectives of the study. Further, theoretical issues and previous studies were also discussed.

\subsection{The Conceptual Issues}

Shadow economy is perceived differently by different scholars because it is difficult to have a generally acceptable definition (Oduh et al, 2008; Ajakaiye \& Akerele, 1996; Thomas, 1992; and Ogbuabor \& Malaolu, 3013). It has been tough to develop a conceptual framework peculiar to the activities of the shadow economy. Accordingly, Smith (1994) defined shadow economy as a "market-based production of goods and services whether legal or illegal that escapes identification in the official estimates of GDP". A more encompassing definition sees the shadow economy as "those economic activities and income derived from them that outwit or otherwise avoid government regulation, taxation or observation". From a government perspective, Oduh et al (2008) described it as an informal enterprise that operates without regulations prescribed by the public authority to govern its organizational behaviour. This suggests that the shadow economy functions without the constraints of behaviour prescribed by public authorities that may include regulation of prices of inputs, control of entry into the sector, unveiling of production process, as well as safety and health standards. By these definitions, the shadow economy should not only be identified with 
illegality but also positive activities that escape tax and other official assessments because of their small size, and its mode of operation. However, the most adopted definition in current literature is that from the International Labour Organisation (ILO) which viewed the informal sector enterprise as "those that employ a handful of workers who earn low income, utilize rudimentary or subsistence technology and operate largely outside the ambiance of government regulations governing business in general (Obada, Odusola \& Akerele, 1996).

Unemployment on the other hand occurs when people are without jobs and they have actively looked for work within the past four weeks (ILO, 1993). It describes a situation in which people who are willing and capable of working are unable to find suitable paid employment. This definition was corroborated by Okafor (2011) who stated that unemployment is a condition where people who are willing to work at the prevailing wages are unable to find jobs. Unemployment has been one of the major macroeconomic problems which every responsible government is expected to monitor and regulate periodically. Its impact is felt mostly by vibrant youths who have never experienced the benefits of paid employment, or by older people who lost their jobs as a result of retrenchment, redundancy, bankruptcy or change in government policies.

\subsection{Review of Theoretical Literature}

In order to support this study, a number of theories have been advanced to further clarify the concept of shadow economy among which are: the modernization, dependency, structural and neo-liberalism theories (Yusuf, 2011; Ogbuabor, Orji \& Mba, 2013; Duru, 2012).

\subsubsection{Modernization Theory}

A shadow economy is characterized by the modernization theory as a social problem caused by the backward socio-economic systems peculiar to less developed countries. According to Rostow (1960), the essence of this policy prescription was for these countries to acquire "modern" values, "modern" legal institutions and political structures and "modern" capitalist economies for evolution. Quintessentially, the issues of shadow economy are not wholly entrenched in capitalist exploitation and extraction, but that the countries have not been fully integrated into the modern or international world. Therefore, these countries take-off and pull alongside with the advanced countries as time evolves. From this theory, the shadow economy surfaces as a residual of traditional, pre-capitalist and subsistence means common to lonely rural areas, endangered outside the modern economy due to scrubby skills and value reorientations.

\subsubsection{Dependency Theory}

This theory was spear-headed by ILO, (1972) and Hart, (1973) who classified this unruly economic activity as the "informal sector". According to Hart, informal or shadow economic activities were not an ordinary addition to traditional subsistence schemes, and members were not objectively subjected to poverty and marginality. Portes and Schauffer, (1992) described workers in the shadow economy as being generally poor and in a presumed negligible position relative to the modern capitalist sector. The shadow economy has been ascribed with the properties of little capital, low technology and production, meager profits, self-employed family labour, easy entry and exit, little competition and efficiency. Summarily, while individuals struggle for survival rather than profit making, firms consistently seek to take advantage of their sheer abilities to evade tax and tight regulations.

\subsubsection{Structuralism}

By this theory, the shadow economy emerged not as a result of excess labour supply or unruly manner but as a replacement for labour and capital utilization. In sharp contrast, Maloney, (2004) defined the informal sector as comprising workers that are categorically 'unregulated' in respect of capital under the confine of capitalist accumulation. The generic feature of the African informal sector, according to Capecchi, (1989) and Ishola, (2008), is identifiable as 'subsistence' informal economy where people are engaged in informal means of raising income.

\subsubsection{Neo-Liberalism Theory}

The theory is based on an ideology of economic laissez- faire in which its philosophy supports economic policies that lessen the role of the state and optimizes private sector business holdings. This theory attempts to explain the transfer of the economy to private individuals from the public sector under the premise that, efficiency can be enhanced and economic well-being improved in the country. De Soto (1989) argued that the informal sector is a reaction to the extreme and tight state regulations and other critical macroeconomic conditions. The theory corroborates the notion that the informal sector is made up of firms that chose to function informally so as to shun the cost of formal registration, and other herculean conditions in the business outfit. The Neo-liberalism school believes in actors producing informally in so far as government rules are burdensome and costly, property rights remain deficient and access to productive resources like finance and technology remain elusive (Duru, 2012). 


\subsection{Review of Related Empirical Literature}

Ogbuabor and Malaolu, (2013) examined the size, development and causes of informal sector in Nigeria. The study used the Error correction multiple indicators and multiple cause (EMIMIC) model to estimate the size, cause and development of informal economy in Nigeria. The results confirmed that, since 1970, the size of the informal economy has ranged from $53.6 \%$ to $77.2 \%$ of GDP and the average size of the informal economy was about $64.6 \%$ of GDP. Consequently, unemployment, tax burden, government regulations and inflation are the driving forces of informality in Nigeria. Oduh et al (2008) estimated the determinants of informality in Nigeria using the MIMIC methodology over the period 1970 to 2005. The study discovered that a fall in income, rise in tax, high black market dividends and government control of the economy are the influential indicators of informality in Nigeria. In a similar study, Fasanya and Onakoya (2012) examined the impact of informal sector on employment generation in Nigeria during the period 1970-2010 using annual time series data. The estimated result affirms that the informal sector impacts positively in absorbing the large pool of labour force in Nigeria. Salisu (2001) employed the MIMIC method in studying the hidden economy in Nigeria. The study showed that the key determinants of informality in Nigeria are the tax rate, inflation and waning per capita income. Also, Salisu, Ariyo and Bekoe (2012) used currency and demand approach to assess the informal sector in Nigeria. The study found that informality in Nigeria is influenced by tax rate, inflation, interest rate, high income inequalities, low productivity of the tax system and complex legislation.

Davidescu, (2014) employed ARDL and SVAR to investigate the impact of the unemployment rate (International Labour Organization, ILO and Recorded) on Romania shadow economy using quarterly data for the period 2000 to 2013. The estimated outcome from the ARDL technique revealed no long-run association between unemployment rates and Romania shadow economy. The result of impulse response function via SVAR confirms that an increase in the recorded unemployment rate led to the rise in the size of shadow economy in the short run, while rise in ILO unemployment rate generated a fall in the size of the shadow economy. Similarly, Davidescu and Dobre (2012) established a causal relationship between unemployment rate and U.S shadow economy using Toda-Yamamoto method for quarterly data over the period 1980 to 2009. The size of the shadow economy was computed as a percentage of the real GDP via a MIMIC model having four causal variables (taxes on corporate income, contributions for government social insurance, unemployment rate and self-employment), and two indicators (index of real GDP and civilian labour force participation rate). The results support a unidirectional causality running from unemployment rate to shadow economy for the United States. Dobre and Alexandru (2009) also employed annual data for the period 1970 - 2007 to estimate the impact of unemployment rate on the dimension of Shadow economy in Spain using Structural Equation Approach (SEA). The estimated result shows a positive relationship between unemployment rate and shadow economy. The model includes the tax burden, social benefits, subsidies, government employment, self-employment and unemployment rate as the main causes of shadow economy, and the result indicates that the size of the informal sector fluctuated between $22 \%$ and $18 \%$ of GDP in the last ten years. In a similar analytical study, Davidescu and Dobre (2013) investigated the relationship between the shadow economy and unemployment rate using a Structural VAR method for quarterly data over the period 1982-2011. Shadow economy was modeled as a latent variable using a special case of the structural equation in the MIMIC model. The impulse response function generated by the SVAR reveals that a rise in the unemployment rate in the formal sector will lead to an increase in the number of people who work in the shadow economy in the short run.

\section{Data and Methodology}

The series of dataset used in this research are quarterly data covering the period 1980Q1 to 2018Q4. The study decomposed the size of the Nigerian Shadow economy expressed as a percentage of the official Gross Domestic Product (SE) driven from Multiple causes (taxes on corporate income, contributions for government social insurance, unemployment rate and self-employment), and indicators (index of real GDP and currency ratio M1/M2) giving rise to MIMIC (4-1-2) model. Other variables include ILO unemployment rate (ILO_UR) and registered unemployment rate (R_UR). To examine the imperatives of the relationship between unemployment rate and shadow economy in Nigeria, the dataset was sourced from the Central Bank of Nigeria (CBN) Statistical Bulletin and National Bureau of Statistics (NBS) Annual Abstract of Statistics for the relevant period. The data have been verified via unit roots using the Augmented Dickey Fuller (ADF) and Philip-Peron's (PP) tests to get rid of spurious results.

\subsection{The General Mimic Model}

The MIMIC model treats the Shadow Economy as a 'latent' (hidden) variable connected to the number of observable indicators (describing the changes in the size of the SE), and on the other hand, to the chain of observed causal variables considered to be the most pertinent contributing factors to shadow economic activities (Dell'Anno, 2003). 
In the process of econometric modeling of the shadow economy in Nigeria, two sets of equations are employed. The equation that connects the relationship between the latent or unobservable variables $(\eta)$ and the causes $\left(X_{q}\right)$ is called the "structural model" while the equation that joins the indicators $\left(Y_{p}\right)$ with the latent or unobservable variables is termed the "measurement model". The MIMIC model of the shadow economy can be expressed as:

$$
\begin{gathered}
Y_{t}=\lambda \eta_{t}+\varepsilon_{t} \\
\eta_{t}=\gamma^{\prime} X_{t}+\xi_{t}
\end{gathered}
$$

Where; $(\eta)$; the scalar of latent variable (comprises of the size of the SE), $Y_{t}^{\prime}=\left(Y_{1}, \ldots \ldots, Y_{p}\right)$, describes the vector of indicators; $X_{t}^{\prime}=\left(Y_{1}, \ldots \ldots, X_{p}\right)$, depicts the vector of causes; $\lambda_{t(p \times 1)}$ and $\lambda_{t(q \times 1)}$, are vectors of parameters; $\varepsilon_{t(p \times 1)}$ and $\xi_{t(q \times 1)}$, explains the vectors of scalar of random error terms, while $\varepsilon_{t}$ and $\xi_{t}$ are presumed to be mutually uncorrelated. Putting equation (2) in (1), the MIMIC model can be re-written as thus:

$$
Y_{t}=\pi X_{t}+Z_{t}
$$

Where; $\pi=\lambda \gamma_{t}, Z_{t}=\lambda \xi+\varepsilon$. The error term $Z_{t}$ in equation (3) depicts ( $\left.p x 1\right)$ vector of linear combinations of the white noise error terms $\varepsilon_{t}$ and $\xi_{t}$ from the structural equation and measurement model that are $Z_{t} \sim(0, \Omega)$. The estimation of equations (1) and (2) entails standardization of the parameters in (1) and a suitable way of achieving this is by limiting one element of $\lambda$ to some previously assigned value (Giles, 1998, 1999).

\subsection{Measures of Shadow Economy}

Index of Real Gross Domestic Product $\left(\mathrm{y}_{1}\right)$ : The choice of this variable in the model is crucial since it is selected as a scale variable (reference variable). This study chose 2002 as the base year of the scale variable because it was the year that the most current country-wide study of the unofficial sector in Nigeria was undertaken (Oduh et al, 2008; Ogbuabor and Malaolu, 2013). The MIMIC method suggests the need to affix scale in order to calculate the rest of the parameters as a function of this scale variable. To avoid ambiguity, the model preempts for allotting positive or negative unit value to the variable to make it easier for the relative magnitude of other indicator variables. However, the nature of the relationship between this variable and the shadow economy is not easily determined (Buehn \& Schneider, 2008; Ogbuabor \& Malaolu, 2013).

Currency ratio $\left(\mathrm{y}_{2}\right)$ : The transactions in the shadow economy are most often done with cash or money drawn instantly from the current account. To measure shadow economy in Nigeria, the ratio of narrow to broad (M1/M2) money has been used as proxy for currency in circulation, as contained in the study by Dell'Anno and Solomon (2006). Thus, consistent with the work of Giles and Tedds, (2002); Buehn and Schneider, (2008); and Ogbuabor and Malaolu, (2013), this study used real currency in circulation (M1) and a positive relationship is anticipated between Shadow Economy and M1. The MIMIC model can be computed by employing maximum Likelihood via the use of LISREL 9.0 package in order to normalize the coefficient of the index of real GDP $\left(\lambda_{1}=-1\right)$ to classify the model adequately. The negative sign depicts an inverse relationship between official and shadow economy. In order to detect the suitable model, the study started with MIMIC model 6-1-2 and variables whose structural parameters are not statistically significant have been knocked out giving rise to a more parsimonious model 4-1-2 fitting the Nigerian Shadow economy as contained in Dobre and Alexandru, (2010) with four causal variables (tax burden, self-employment, social benefits paid by the government and unemployment rate) and two indicators (index of real GDP and currency ratio (M1/M2)).

Once the size of the Nigerian shadow economy has been estimated, there is cogent need to ascertain the nature of the relationship between unemployment and shadow economy by applying the Toda-Yamamoto approach. Toda and Yamamoto (1995) causality is used in level Vector Autoregressive (VARs) irrespective of whether the variables are integrated, cointegrated or not. The Toda-Yamamoto approach explains that the F-statistic used to test for traditional Granger causality may not be valid as the test does not have a standard distribution when the time series data are integrated or cointegrated. The Toda-Yamamoto technique primarily includes valuation of an augmented $V A R^{K+d \max )}$ model, where $k$ the optimal lag length is in the original VAR system and $d$ max is the maximum order of integration of the variables in the VAR system. To be consistent with the thrust of this study, the Toda-Yamamoto causality test submits a modified Wald (MWald) test statistic to zero restrictions on the parameters of the original VAR $(\mathrm{k})$ model. The test has an asymptotic chi-square $\left(\mathrm{X}^{2}\right)$ distribution with $\mathrm{k}$ degrees of freedom. 
The Toda-Yamamoto approach is mostly sub-divided into two phases. The first step determines the optimal lag length (k) and the maximum order of integration (d) of the variables in the system. The lag length (k) is gotten through a process of VAR in levels among the variables in the system by using dissimilar lag length criterion such as Akaike Information Criterion (AIC) or Schwarz Bayesian Information Criterion (SBC). The unit root tests have been used to detect the order of integration (d) of the model using Augmented Dickey Fuller (ADF) test. The second phase employed the modified Wald (MWALD) procedure to verify the VAR $(\mathrm{k})$ model for causality. The optimal lag length is equal to $[P=(k+d\{\max \}]$. In case of bivariate (Y, X) relationship, Esso, (2010) demonstrated the Toda-Yamamoto (1995) causality test as established below:

$$
\begin{gathered}
\mathrm{Y}_{t}=\phi_{\mathrm{O}}+\sum_{t=1}^{k} \beta_{1 t} \mathrm{Y}_{t-1}+\sum_{t=k+1}^{k+d \max } \beta_{2 t} \mathrm{Y}_{t-1}+\sum_{t=1}^{k} \delta_{1 t} \mathrm{X}_{t-1}+\sum_{t=k+1}^{k+d \max } \delta_{2 t} \mathrm{X}_{t-1}+\varepsilon_{1 t} \\
\mathrm{X}_{t}=\varphi_{\mathrm{O}}+\sum_{t=1}^{k} \omega_{1 t} \mathrm{X}_{t-1}+\sum_{t=k+1}^{k+d \max } \omega_{2 t} \mathrm{X}_{t-1}+\sum_{t=1}^{k} \rho_{1 t} \mathrm{Y}_{t-1}+\sum_{t=k+1}^{k+d \max } \rho_{2 t} \mathrm{Y}_{t-1}+\varepsilon_{2 t} .
\end{gathered}
$$

Where $Y_{t}$; shadow economy, $X_{t}$; unemployment rates and $\phi_{0} \varphi_{0}$ depicts the intercepts, $\beta_{1 t}, \beta_{2 t}, \delta_{1 t}, \delta_{2 t}, \omega_{1 t}, \omega_{2 t}, \rho_{1 t}, \rho_{2 t}$, and $\varepsilon_{1 t}, \varepsilon_{2 t}$ represents the parameters of the model and are the residuals of the model assumed to be white noise. The Wald tests were then employed on the first $\mathrm{k}$ coefficients matrices using the standard $X^{2}$ statistic (Duasa, 2007).

Let $\delta_{t}=\operatorname{vec}\left(\delta_{11}, \delta_{12}, \ldots, \delta_{1 k}\right)$ be the vector of the first $\mathrm{k}$ VAR coefficients. However, the study is guided by the following null hypotheses: The Null hypothesis that $\mathrm{X}$ does not cause $\mathrm{Y}$ is formulated as thus:

$$
H_{0}: \delta_{1 i}=0, i=1, \ldots \ldots \ldots \ldots \ldots \ldots, K .
$$

Equally, the second null hypothesis that $\mathrm{Y}$ does not granger causes $\mathrm{X}$ is built as follows:

$$
H_{0}: \rho_{1 t}=0, i=1, \ldots \ldots \ldots \ldots \ldots \ldots \ldots . ., K .
$$

Equations 4 and 5 are assessed using the Seemingly Unrelated Regression (SUR) approach (Rambaldi \& Doran, 1996). The hypothesis is tested via Modified Wald test whose asymptotic chi-square $\left(X^{2}\right)$ distribution has $k$ degree of freedom.

\section{Empirical Results}

\subsection{Robustness of Shadow Economy}

It is an arduous and tasking exercise computing the robustness of the size and trend of the shadow economy. However, the techniques drawn for estimating the size and trend of the SE such as currency demand approach and/or electricity (physical input) approach treats just one indicator that must capture all effects of the shadow economy. This study is therefore based on the statistical approach of latent (unobserved) variables known to be multiple causes and multiple indicators (MIMIC) which mulled over the causes leading to the survival and proliferation of the shadow economy alongside the multiple effects of shadow economy over time. The most parsimonious model (MIMIC 4-1-2) identified include four causal variables (taxes on corporate income, contributions for government social insurance, unemployment rate and self-employment), and two indicators (index of real GDP and currency ratio $\mathrm{M} 1 / \mathrm{M} 2)$.

Bearing in mind the reference variable $\left(Y_{t}, \frac{\text { Real } G D P}{\text { Real } G D P_{2002}}\right)$, the shadow economy which can be scaled up to the value in 2002, the base year which sets the bases for other averages to be estimated from this year for Nigerian Shadow economy, is presented in Table 1.To be precise, the index of changes of the SE $(\eta)$ in Nigeria evaluated as a percentage of GDP in the year 2002 is connected to the index of the changes of the real GDP as shown below:

Measurement Equation: 


$$
\frac{G D P_{t}-G D P_{t-1}}{G D P_{2002}}=\frac{\widetilde{\eta_{t}}-\widetilde{\eta_{t-1}}}{G D P_{2002}}
$$

Table 1. Estimate of the size of the Nigerian shadow economy (2002)

\begin{tabular}{lll}
\hline Author & Method & Size of Shadow Economy \\
\hline Johnson et al, (1998) & Currency demand approach & $13.9 \%$ \\
\hline Lacko (1999) & Physical input(electricity) & $10.5 \%$ \\
\hline Schneider \& Enste, (2000) & Currency demand approach & $7.5 \%$ \\
\hline Mean 2002 & & $10.6 \%$ \\
\hline
\end{tabular}

The structural model computed is used to find a numerical time series index for the unobserved economy. The structural equation therefore is obtained as:

$$
\frac{\Delta \tilde{\eta}_{t}}{G D P_{2002}}=-0.42 \Delta X_{1 t}+1.24 \Delta X_{2 t}+0.89 X_{3 t}+2.10 X_{4 t}
$$

The index is scaled to take up a value of $10.6 \%$ in 2002 and further transformed in respect to the GDP in the 2002 to the SE as ratio of current GDP demonstrated in the following equations:

$$
\frac{\tilde{\eta}_{t}}{G D P_{2002}} X \frac{\tilde{\eta}_{2002}}{G D P_{2002}} X \frac{G D P_{2002}}{\tilde{\eta}_{2002}} X \frac{G D P_{2002}}{G D P_{t}}=\frac{\tilde{\eta}_{t}}{G D P_{t}}
$$

Where $\frac{\widetilde{\eta_{t}}}{G D P_{2002}}$, depicts the index of Shadow economy computed by equation (6), $\frac{\eta_{2002}}{G D P_{t}}=10.6 \%$ denotes the estimate of SE from the outside the system, $\frac{G D P_{2002}}{\widetilde{\eta}_{2002}}$, describe the value of the index calculated by equation (6). $\frac{G D P_{2002}}{G D P_{t}}$, have been used to convert the index of changes in the base year of the Shadow economy in respect to the current GPD and $\frac{\dot{\vec{\eta}}}{G D P_{t}}$, represents the computed Shadow economy as a percentage of the official GDP. The size of the shadow economy as a percentage of the official GDP is represented in the graph depicted below:

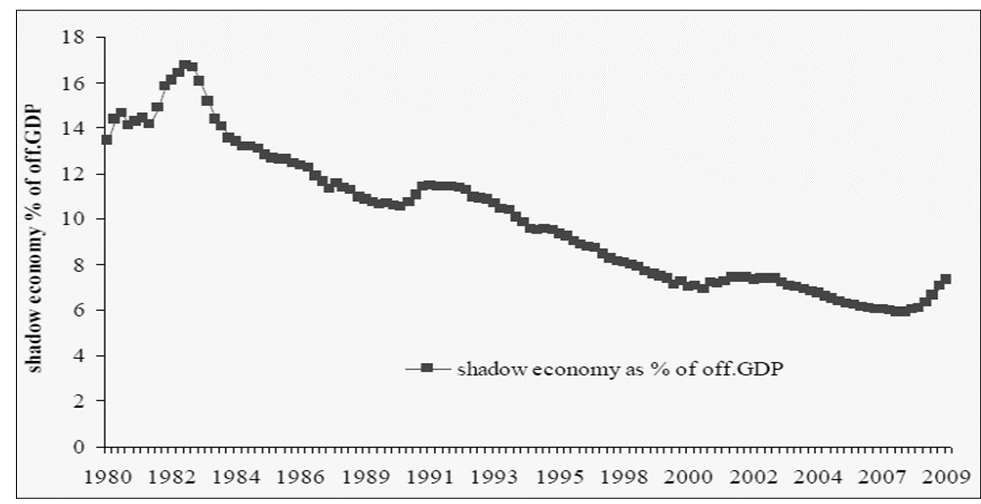

Figure 1. Size of Shadow economy in Nigeria as a percentage of official GDP 
It is evident from the table above that the shadow economy as a percentage of official GDP accounted for $13.78 \%$ at the start of the first quarter of 1980 and oscillates downward after recording the value of $8.23 \%$ in the third quarter of 2009. From the beginning of 1983, the amount of unofficial economy averaged 6.4\% of GDP and at the end of 2007, it starts to decline. For the last two years of 2008 and 2009, the size of the unrecorded economy increased gradually, attaining the value of $8.23 \%$ in the third quarter of 2009 which continued to 2014. The results of the downward trend of unregulated economy in Nigeria however concurred with previous empirical studies undertaken by Enste, (2003); Schneider, (2007, 2009); Albu, (2010, 2011); Davidescu \& Dobre, (2012), Davidescu, (2014a).

\subsection{Relationship Between Unemployment Rate and Nigerian Shadow Economy}

It has been revealed over time by empirical studies that the enormous cause of the shadow economy is the tax burden alongside the unemployment rate. In keeping with the work of Giles and Tedds (2002), two divergent forces clarify the connection between unemployment rate and shadow economy. An increase in the unemployment rate may include a decrease in the unofficial sector because it is positively correlated to the expansion of GDP, and consequently aligned to unemployment rate thereby negatively satisfying Okun's law. On the other hand, increase in unemployment rate leads to an increase in the number of people working in the unregulated economy since they have more time for such activities. Dell'Annon and Solomon (2007) confirmed a positive association between unemployment rate and shadow economy of U.S in the short run. The relationship between aggregated unemployment rate (ILO and Registered) and shadow economy in Nigeria is expressed below in Figure 2.

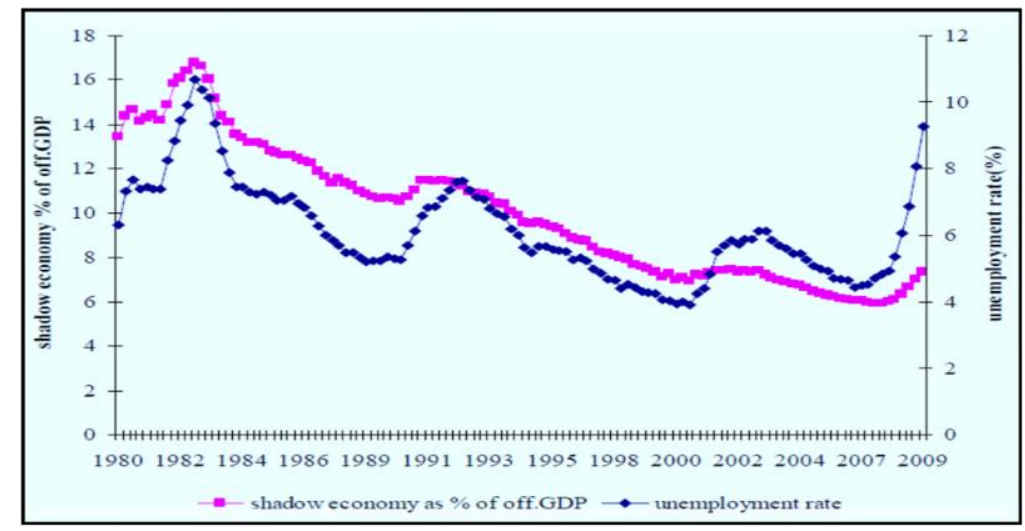

Figure 2. Unemployment rate and shadow economy in Nigeria

The existence of a strong and positive association between unemployment rate and shadow economy is affirmed by the estimated coefficient of determination (0.89).

\subsection{A Tado-Yamamoto Approach to the Relationship Between Unemployment Rate and Shadow Economy in Nigeria}

The estimation of causality test through the Tado-Yamamoto approach has been done in three stages. First, the order of integration of the variables is determined. Second, the maximum lag length is decided using Akaike Information Criterion (AIC) and Schwarz Bayesian Information Criterion (SIC). Finally, the non-causality test between shadow economy and registered unemployment rate (R_UR) on the one hand, and between shadow economy and ILO unemployment rate (ILO_UR) on the other hand, exploring the modified Wald (MWALD) test is conducted. Preceding the Tado-Yamamoto non-causality test, the variables are determined via Augmented Dickey-Fuller (ADF) and Philip-Peron's (PP) unit root tests to ward off any tendency of having a spurious result. The results from table 2 confirmed that, all the variables are integrated of order one I(1) because the null hypothesis is rejected at the first difference. Hence, the maximum order of integration using the VAR system is $d_{\max }=1$. Given that, both series were found to be integrated of order one, the bivariate VAR model has been specified by determining the maximum lag length of all level variables in the model. The optimal lag length (k) chosen by AIC, SIC, FPE, HQ and LR is 6*. However, the study employed the estimate of VAR (5) for registered unemployment model and VAR (4) for ILO unemployment rate model. 
Table 2. ADF and PP unit root test

\begin{tabular}{|c|c|c|c|c|c|c|c|c|c|c|}
\hline & & \multicolumn{3}{|c|}{ Shadow Economy (SE) } & \multicolumn{3}{|c|}{$\begin{array}{l}\text { Registered } \\
\text { rate }\left(\mathbf{R} \_U R\right)\end{array}$} & \multicolumn{2}{|c|}{$\begin{array}{l}\text { ILO-unemployment } \\
\text { (ILO_UR) }\end{array}$} & \multirow{2}{*}{$\begin{array}{l}\text { rate } \\
\text { None }\end{array}$} \\
\hline \multirow{4}{*}{ Level } & & $\mathrm{T} \& \mathrm{C}$ & $\mathrm{C}$ & None & $\mathrm{T} \& \mathrm{C}$ & $\mathrm{C}$ & None & $\mathrm{T} \& \mathrm{C}$ & $\mathrm{C}$ & \\
\hline & ADF & -3.12 & -1.10 & -5.19 & 0.12 & -2.01 & -0.43 & -1.05 & -2.17 & -1.23 \\
\hline & $\mathrm{k}$ & 0 & 5 & 5 & 3 & 3 & 3 & 0 & 0 & 1 \\
\hline & PP & -2.01 & -2.20 & -0.01 & -0.78 & -2.12 & -1.34 & -2.71 & -1.23 & -0.70 \\
\hline \multirow{5}{*}{ 1st dif. } & $\mathrm{K}$ & 3 & 3 & 1 & 0 & 1 & 1 & 4 & 0 & 2 \\
\hline & $\mathrm{ADF}$ & $-9.36^{*}$ & $-10.01 *$ & $-11.24 * *$ & $-4.11 * *$ & $-3.89 * *$ & $-2.86 * *$ & $-5.17 *$ & $-6.34 * *$ & $-3.89 *$ \\
\hline & $\mathrm{K}$ & 0 & 0 & 0 & 4 & 4 & 4 & 2 & 2 & 2 \\
\hline & $\mathrm{PP}$ & $-4.98 *$ & $-8.43 * *$ & $-7.14^{*}$ & $-7.34 * *$ & $-7.29 *$ & $-7.06^{*}$ & $-6.89 *$ & $-6.85^{*}$ & $-7.52 * *$ \\
\hline & $\mathrm{K}$ & 3 & 2 & 4 & 6 & 1 & 1 & 5 & 5 & 5 \\
\hline
\end{tabular}

Note: $\mathrm{T} \& \mathrm{C}$ depicts the general model which comprises drift as well as trend; $\mathrm{C}$ is the model with the drift and without trend; none is the restricted model without a drift and trend. ' $k$ ' denotes maximum lag length decided by AIC, SIC, FPE, HQ and LR setting 12 as the maximum lag to remove serial correlations from the residuals. In using PP, the ' $\mathrm{k}$ ' represents Newey-West Bandwidth decided by Bartlett-Kernel while the *, ** and *** describe rejection of the null hypothesis at $10 \%, 5 \%$ and $1 \%$ levels accordingly.

In applying the Tado-Yamamoto test, an extra lag had to be added to the variables of each equation in order to accommodate the Modified Wald (MWALD) in ascertaining if the coefficients of the lagged variables (aside the extra variable) were equally zero in the equations (Duasa, 2007). By using the seemingly unrelated regression (SUR) structure, VAR (5) for registered unemployment rate model can be specified as follows:

$$
\begin{aligned}
& \mathrm{X}_{t}=\lambda_{0}+\lambda_{1} \mathrm{X}_{t-1}+\lambda_{2} \mathrm{X}_{t-2}+\lambda_{3} \mathrm{X}_{t-3}+\lambda_{4} \mathrm{X}_{t-4}+\lambda_{5} \mathrm{X}_{t-5}+\lambda_{5} \mathrm{X}_{t-5}+\mu_{t}
\end{aligned}
$$

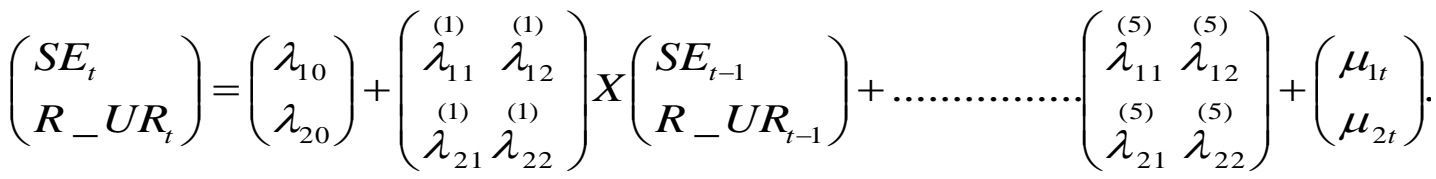

Where

$$
\begin{aligned}
& E\left(\mu_{t}\right)=\left[\begin{array}{l}
\mu_{1 t} \\
\mu_{2 t}
\end{array}\right]=0 \\
& E\left(\mu_{t}, \mu_{t}^{\prime}\right)=\sum
\end{aligned}
$$

To test that, R_UR does not granger cause shadow economy in Nigeria, VAR (5) model has been estimated to verify that $\mathrm{R}_{-} \mathrm{UR}_{\mathrm{t}-1} \ldots \ldots . \mathrm{R}_{-} \mathrm{UR}_{\mathrm{t}-5}$ does not appear in the SE equation. Therefore, the null hypothesis is:

$$
H 0: \stackrel{(1)}{\lambda}_{12}^{(2)}=\lambda_{12}^{(3)}=\lambda_{12}^{(4)}=\lambda_{12}^{(2)}=0
$$

Where ${ }^{\lambda}{ }_{12}^{(i)}$ are the coefficients of $R_{-} U R_{t-1}, i=1 \ldots, 4$ from the first equation of the model. The existence of causality streaming from registered unemployment rate to shadow economy can be established by rejecting the stated hypothesis which mandates finding the significance of the MWald statistic for grouped of the lagged independent variables identified above. Through the same approach, the SUR framework of VAR (4) model has been used to 
establish the causal relationship between ILO unemployment rate and shadow economy in Nigeria as specified below:

$$
\begin{array}{r}
\mathrm{X}_{t}=\alpha_{0}+\alpha_{1} \mathrm{X}_{t-1}+\alpha_{2} \mathrm{X}_{t-2}+\alpha_{3} \mathrm{X}_{t-3}+\alpha_{4} \mathrm{X}_{t-4}+\alpha_{4} \mathrm{X}_{t-4}+\varepsilon_{t} . \\
{\left[\begin{array}{l}
S E_{t} \\
I L O_{-} U R_{t}
\end{array}\right]=\left[\begin{array}{l}
\alpha_{10} \\
\alpha_{20}
\end{array}\right]+\left[\begin{array}{cc}
(1) & (1) \\
\alpha_{11} & \alpha \\
(1) & (1) \\
\alpha_{21} & \alpha_{22}
\end{array}\right] X\left[\begin{array}{l}
S E_{t-1} \\
I L O_{-} U R_{t-1}
\end{array}\right]+. .\left[\begin{array}{cc}
(4) & (4) \\
\alpha_{11} & \alpha_{12} \\
(4) & (4) \\
\alpha_{21} & \alpha_{22}
\end{array}\right]+\left[\begin{array}{l}
\varepsilon_{1 t} \\
\varepsilon_{2 t}
\end{array}\right] .}
\end{array}
$$

To affirm that ILO_UR does not granger causes Shadow economy, the study estimated the VAR (4) model and proved that, $I L O_{-} U R_{t-1} \ldots . . ., I L O_{-} U R_{t-4}$ does not appear in the Shadow economy equation.

Therefore, the null hypothesis is:

$$
H 0: \stackrel{(1)}{\alpha_{12}}=\stackrel{(2)}{\alpha_{12}}=\stackrel{(3)}{\alpha_{12}}=0
$$

(i)

Where $\alpha_{12}$ explains the coefficients of $I L O_{-} U R_{t-1}, i=1,2,3$ in the first equation of the system.

However, the causality running from ILO unemployment rate to Shadow economy can be evaluated by rejecting the above null hypothesis which implies estimating the level of significance of the MWald statistic for the group of the lagged independent variables. In spite of the order of integration of each variables to be an I(1) process (dmax=1), the Tado-Yamamoto causality used d $\max =2$ affirming the likely tendencies of macroeconomic variables to be integrated of at most two $\mathrm{I}(2)$. Therefore, the causality test results of $\mathrm{d} \max =1$ and $\mathrm{d}$ max $=2$ are illustrated below.

Table 3. Tado-Yamamoto causality test result for, $\mathrm{d} \max =1$

\begin{tabular}{llllll}
\hline & Null hypothesis & P & MWald-statistic & P-Value & Decision \\
\hline \multirow{2}{*}{$\mathrm{K}=5$} & H0:R_UR does not granger cause SE & 6 & 12.45 & $0.0010^{*}$ & Reject H0 \\
\cline { 2 - 6 } & H0: SE does not granger cause R_UR & 6 & 8.23 & 0.1380 & Do not reject H0 \\
\hline \multirow{2}{*}{$\mathrm{K}=4$} & H0: ILO_UR does not granger cause SE & 5 & 18.34 & $0.000^{* *}$ & Reject H0 \\
\cline { 2 - 6 } & H0: SE does not granger cause ILO_UR & 5 & 10.348 & 1.023 & Do not reject H0 \\
\hline
\end{tabular}

The asterisk * and ** described rejection of the null hypothesis at $1 \%$ and $5 \%$ level of significance

Table 4. Tado-Yamamoto causality test for, $\mathrm{d}$ max $=2$

\begin{tabular}{llllll}
\hline & Null hypothesis & P & MWald statistic & P-Value & Decision \\
\hline $\mathrm{K}=5$ & H0:R_UR does not granger cause SE & 7 & 14.17 & $0.000^{*}$ & Reject H0 \\
\cline { 2 - 6 } & H0: SE does not granger cause R_UR & 7 & 0.891 & 1.642 & Do not reject H0 \\
\hline \multirow{2}{*}{$\mathrm{K}=4$} & H0: ILO_UR does not granger cause SE & 6 & 22.07 & $0.002^{* *}$ & Reject the H0 \\
\cline { 2 - 6 } & H0: SE does not granger cause ILO_UR & 6 & 5.34 & 0.289 & Do not reject H0 \\
\hline
\end{tabular}

The asterisk * and ** indicates rejection of the null hypothesis at $1 \%$ and $5 \%$ level of significance respectively.

The findings of Tado-Yamamoto causality test from table 3 revealed that, there is a uni-directional movement streaming from registered and ILO unemployment rate to Shadow economy in Nigeria at 1\% and 5\% level of significance thereby rejecting the null hypothesis of non-causality. Similarly, results from table 4 corroborated the unidirectional causality test from table 3 running from registered and ILO unemployment rate to the volume of 
shadow economy in Nigeria at $d \max =2$. This result is similar to the findings of Davidescu, (2014a), Davidescu and Dobre, (2012)

\section{Conclusion}

The study investigated the nature of the relationship between unemployment rate and the size of the shadow economy in Nigeria as a percentage of official gross domestic product using the Tado- Yamamoto approach over the period 1980Q1 to 2018Q4. The size of the shadow economy in Nigeria was determined using the parsimonious model of MIMIC (4-1-2) having four multiple causes (tax burden, self-employment, social benefits paid by the government and unemployment rate) and two indicators (index of real GDP and currency ratio (M1/M2). The estimated relationship of the size of the shadow economy as a percentage of official GDP recorded $13.78 \%$ at the beginning of the first quarter of 1980 before fluctuating until it reached the value of $8.23 \%$ in the third quarter of 2009. The existence of a strong and positive association between unemployment rate and shadow economy is affirmed by the estimated coefficient of determination (0.89). Thus, the capacity of the shadow economy to absorb the large pool of unemployed workers from the official economy in Nigeria has been confirmed by this study. Evidence exists from the Tado and Yamamoto (1995) causality test which revealed a causal association between registered and ILO unemployment to shadow economy. This was further confirmed by the Modified Wald (MWald) test which demonstrated that a strong unidirectional causality emanating from registered and ILO unemployment rate to the size of the shadow economy at $1 \%$ level of significance exists.

Based on the findings of the study, it is recommended that the government should formulate policies capable of inhibiting persistent involvement in the shadow economy by unemployed workers which may alter the planned equitable sharing of social security system (SSS) provided to stimulate the possible "dependency trap". Also, income from the shadow economy, which is most often augmented by social security payments, should be removed in order to discourage full participation in the official economy. This can be done by bringing every sole proprietorship and partnership operating in the parallel market under proper government monitoring and scrutiny.

\section{References}

Abumere, S. I. (1995). "The informal sector in Nigeria's development process" lesson from the literature. A Paper Presented at Development Policy Centre, Ibadan.

Adedoyin, I. L., Dahunsi, S. O., Babajide, A. A., Asaleye, J. O. I., Inegbedion, H., Manasseh, C. O., \& Lawal-Adedoyin. (2020). Examining the Effects of Oil Price Long Memory and Exchange Rate Long Memory on Stock Market Behavior in Nigeria. International Journal of Energy Economics and Policy, 10(4), 430-436.

Ajakaiye, O., \& Akerele, W. O. (1996). Overview of Conceptual and Methodological Issues in Informal sector Research. In Conceptual and methodological framework for informal sector research in Nigeria (pp. 7-26). CBN/NISER Informal Sector Study.

Albu, L. L., Ghizdeanu, I., \& Stanica, C. (2011). Spatial distribution of the international economy. A Theoretical and Empirical Investigation, 1, 63-80.

Albu, L. L., Iorgulescu, R., \& Stanica, C. (2010). Estimating hidden economy and hidden migration: the case of Romania. Romania Journal for Economic Forecasting, 11(2), 46-56.

Ariyo, A., \& Bekoe, W. (2012). Currency demand, the underground economy and tax evasion: The case of Nigeria. Journal of Monetary and Economic Integration, 11(2).

Boeri, T., \& Garibaldi, P. (2002). Shadow Activity and Unemployment in a depressed labour market. CEPR Discussion Papers, 3433.

Buehn, A., \& Shcneider, F. (2008). MIMIC models, cointegration and error correction: an application to the french economy. IZA Discussion Paper, 3306, 1-30.

Capecchi, V. (1989). The informal economy and the development of flexible specialization in Emilia Romagna. In A. Portes, et al.. (Ed.), The informal economy (pp. 189-215). Baltimore: Johns Hopkins University Press.

Central Bank of Nigeria. (2004). Statistical bulletin. Retrieved from htt://www.cenbank.or

Davidescu, A. (2014). Investigating the impact of unemployment rate on the Romanian shadow economy. A complex approach based on ARDL and SVAR analysis. Romanian Journal of Economics Forecasting, 17(4), 109-127. 
Davidescu, A. A. (2014a). Revisiting the relationship between unemployment rates and shadow economy. A Tado-Yamamoto approach for the case of Romania. 7th International Conference on Applied Statistics, Procedia Economics and Finance (Vol. 10, pp. 227-236.). Retrieved from www.sciencedirect.com

Davidescu, A., \& Dobre, I. (2012). The causal relationship between unemployment rate and U.S shadow economy. A Tado-Yamamoto approach. Journal of Social and Economic Statistics, 1(1), 21-34.

Davidescu, A., \& Dobre, I. (2013). Revisiting the relationship between shadow economy and the level of unemployment rate: A SVAR empirical investigation for the case of United States. Journal of Applied Quantitative Methods, 8(3), 11-19.

Dell' Anno, R., \& Solomon, O. H. (2007). Shadow economy and unemployment rate in USA: is there a structural relationship? An empirical analysis. Applied Economics, 1-19.

Dell'Anno, R. (2003). Estimating the shadow economy in Italy: a structural equation approach. Department of Economics, University of Aarhus, Demark.

Desoto, H. (1989). The other path: The economic answer to terrorism. New York, Harper and Row Publishers.

Dobre, I., \& Alexandru, A. (2009a). The impact of unemployment rate on the dimension of shadow economy in Spain: A Structural equation approach, European research studies. European Research Studies Journal, 13(4), 179-197.

Dobre, I., \& Alexandru, A. (2010). A non-parametric analysis of the relationship between unemployment rate and shadow economy using local polynomial regression models. Economic Computations and Economic Cybernetics Studies and Research, 44(1), 21-44.

Duasa, J. (2007). Malaysian Foreign direct investment and growth: does stability matters?. Journal of Economic Cooperation, 28(2), 83-98.

Duru, M. (2012). Nigeria's informal sector: opportunities for self-employment and income generation. Economics and Finance Review, 1(11), 35-41. Retrieved from http://www.businessjournalz.org/efr

Enste, D. H. (2003). Shadow economy and institutional change in transition countries. In B. Boyan (Ed.), The informal economy in the eu assessment countries: size, scope, trends and challenges of the process of EU-enlargement (pp. 81-114). Centre for study Democracy, Sofia.

Esso, J. L. (2010). Long-run relationship and causality between foreign direct investment and growth: evidence from ten African countries. International Journal of Economics and Finance, 2(2), 168-177.

Fasanya, I. O., \& Onakoya, A. B. O. (2012). Informal sector and employment Generation in Nigeria: an error correction model. Research on Humanities and Social Sciences, 2(7), 48-55.

Feige, E. L. (1990). Defining and estimating underground and informal economies: The new institutional economics approach. World Development, 18(7), 989-1002.

Giles, D. E. A. (1998). Measuring the hidden economy: implications for econometric modelling. The Economic Journal, 109(456), 370-380.

Giles, D. E. A. (1999). Modelling the hidden economy and the tax gap in the New Zealand. University of Victoria.

Giles, D. E. A., \& Tedds, L. M. (2002). Taxes and the Canadian underground economy. Canadian Tax foundation, Canadian paper 106. Canada: Toronto.

Hart, K. (1973). Informal Income Opportunities and Urban Employment in Ghana. Journal of Modern African Studies, 2.

ILO. (1976). UNDP: Development of Informal Sector in Java, Indonesia. Report prepared by S.V. Sethuraman under the ILO/UNDP Project No. INS/72/030 Geveva.

International Labour Organization (ILO). (1972). Employment, income and equality: a strategy for increasing productivity in Kenya. ILO Monograph, Geneva, 1145-1282.

International Labour Organization (ILO). (1993). Resolutions Concerning Statistics of Employment in the Informal Sector. 15th International Conference of Labour Statisticians (p. 5), January.

Ishola, R. A. (2008). Reducing unemployment through the informal sector: A case study of Nigeria. European Journal of Economics, Finance and Administrative Sciences, 11.

Maloney, W. F. (2004). Informality revisited. World Development, 32(7), 1159-1178. 
Obadan, M. I., Odusola, A. F., \& Akerele, W. O. (1996). Strategies for revisiting the Nigerian economy: The role of informal sector. Paper presented at the Seminar of the Nigerian Economic Society Lagos, Jan. 6.

Oduh, M., Eboh, E., Ichoku, H., \& Ujah, O. (2008). Measurement and explanation of informal sector of the Nigeria. AIAE Research Paper, 3, 1-64.

Ogbuabor, E. O., Orji, A., \& Mba, I. C. (2013). Trade liberalization-Implication for Informality in Nigeria. International Journal of Research in Arts and Social Sciences, 6, 219-228.

Ogbuabor, J. E., \& Malaolu, V. A. (2013). Size and causes of the informal sector of the Nigerian economy: Evidence from error correction MIMIC Model. Journal of Economics and Sustainable Development, 4(1), 85-103.

Okafor, E. E. (2011). Youth Unemployment and Implications for Stability of Democracy in Nigeria. JSDA, 13(1). Retrieved from http://wwww.jsdafrica.com/JsdaV13No1_Spring2011

Olowu, D., \& Okotoni, O. (1996). The informal sector in Nigeria: some analytical and development issues. In Conceptual and Methodological Framework for Informal Sector in Nigeria (pp. 27-40). CBN/NISER Informal Sector study.

Omisakin, I. S. (1999). Factors influencing success or failure of an enterprise in informal sector. NISER Monograph Series, 6, 11-54.

Portes, A., \& Schauffler, R. (1992). The informal economy in Latin America: Definition, measurement and policies. Programme in Comparative International Development. Working paper No. 5, Development of Sociology, John Hopkins University, Baltimore MD21218 USA.

Rambaldi, A., \& Doran, H. (1996). Testing for granger non-causality in cointegrated systems made easy. Working Papers in Econometrics and Applied Statistics, Department of Econometrics, University of New England.

Rostow, W. W. (1960). The five stages of growth: A summary in the stages of Economic Growth: A Non-Communist Manifesto (pp. 4-16). Cambridge, Massachusetts: Cambridge University Press.

Salisu, M. (2001). Incentive structure, civil service efficiency and the hidden economy in Nigeria. World Bank Institute for Development Economic Research (WIDER).

Schneider, F. (2007). Reducing the shadow economy in germany: a blessing or a curse?. Department of Economics Discussion Paper, University of Linz, Linz.

Schneider, F. (2009). Shadow Economies and corruption all over the world: New estimates for 145 countries. Economics, 1-47.

Schneider, F., \& Enste, D. (2000). Shadow Economies: Size, Causes and consequences. Journal of Economic Literature, 38, 73-110.

Tanzi, V. (1999). Uses and abuses of estimates of the underground economy. Economic Journal, 109, 338-347.

Thomas, J. J. (1992). Informal Economic Activity. New York, London, Harvester Wheatsheaf.

Toda, H. Y., \& Yamamoto, H. (1995). Statistical inference in vector auto regressions with possibly integrated processes. Journal of Econometrics, 66, 225-250.

Yusuff, O. S. (2011). A theoretical analysis of the concept of informal economy and informality in developing countries. European Journal of Social Sciences, 20(4), 624-636.

\section{Copyrights}

Copyright for this article is retained by the author(s), with first publication rights granted to the journal.

This is an open-access article distributed under the terms and conditions of the Creative Commons Attribution license (http://creativecommons.org/licenses/by/4.0/). 